\title{
What do we know about how to improve vaccine uptake?
}

\author{
Naus $\mathbf{M}^{1^{*}}$ \\ ${ }^{1}$ BC Centre for Disease Control and School of Population and Public Health, University of British Columbia, Vancouver, BC \\ "Correspondence: monika.naus@bccdc.ca
}

\begin{abstract}
Over the past 100 years, an increasing array of vaccines has been introduced into the Canadian market and yet optimal use depends on public demand and acceptance of these products. In the 1990s, research focused on key barriers to vaccine uptake, highlighting the importance of barriers to access and "missed opportunities" for vaccination. In this century the focus is on vaccine hesitancy, which is influenced by factors such as complacency, convenience and confidence. This phenomenon is not new but some of its drivers include an increasingly crowded immunization schedule, heightened societal concerns about risk over benefit, and a rise in health consumerism. Understanding and addressing vaccine hesitancy will be critical to preventing it from undermining the success of immunization in the future. While more research is needed, there are both practitioner-based resources to optimize dialogue with vaccine-hesitant parents and program-based resources to address vaccine hesitancy at a population-based and societal level.
\end{abstract}

\section{Introduction}

Parental decisions to not vaccinate their children are recognized as an increasing barrier to the success of immunization programs in Canada. On the heels of successful elimination of measles and rubella in Canada (1) have come the challenges of introduction of HPV vaccine (2), an unflattering report card on vaccine coverage rates for Canada from UNICEF (3), provincial monitoring indicative of a growing trend in vaccine refusal (4), and re-emergence of measles (5). All of these have shed light on an important contributor to vaccine uptake, now termed "vaccine hesitancy." This phenomenon is not new but some of its drivers include an increasingly crowded immunization schedule, heightened societal concerns about risk over benefit, and a rise in health consumerism. Understanding and addressing vaccine hesitancy is critical to prevent it from undermining the success of immunization in the future. The objective of this article is to summarize the available literature on strategies for addressing vaccine hesitancy in an effort to improve public confidence and, correspondingly, vaccine acceptance.

In the past 100 years, scientists and academics, the vaccine industry, and regulatory agencies have brought an array of vaccines for primary prevention of serious diseases to the Canadian market. Since the 1960s, the National Advisory Committee on Immunization (NACl) has made recommendations for their use (6). Provincial/ territorial ministries of health adopt these into publicly-funded immunization programs. Thereafter it is the primary objective of public health immunization programs to achieve high targeted levels of vaccine uptake in the population in order to maximize the benefits of this preventive measure (7).

In the 1990s, the large outbreaks of measles which occurred prior to introduction of the second dose of measles vaccine into routine childhood immunization led to program-based research focusing on key barriers to vaccine uptake. Emerging especially from the U.S.-based studies was a body of work addressing the importance of "missed opportunities" for vaccination. This highlighted that a significant contribution to ongoing outbreaks was under-vaccination among children who had encountered a health care provider who failed to use the visit as an opportunity to offer vaccine. Recommendations to improve provider-driven interventions were developed, and several systematic reviews were conducted in the United States and Canada to guide incorporation of strategies with demonstrated effectiveness into guidelines for provider practice $(8,9,10,11)$. These are well summarized by the Community Preventive Services Task Force and include reminder/recall systems, vaccination requirements and programs for day care centres and schools/colleges, home visits, immunization information systems, client and family incentives, and provider assessment and feedback (12). In a more recent development, evidence- 
based pain reduction techniques have been incorporated into immunization practice guidelines to reduce reasons why people may choose not to immunize (13).

\section{Analysis}

The literature on parental factors associated with vaccine uptake contains many studies of immunization-related knowledge, attitudes and behaviours, and attempts have been made to identify characteristics of individuals and populations objecting to vaccination (14). The term "vaccine hesitancy" has come into use to describe attitudes and beliefs that may interfere with acceptance of one or more vaccines, including parental requests for alternate immunization schedules. Vaccine hesitancy is associated with a spectrum of vaccine uptake, from acceptance of vaccines despite doubts, to selective vaccination, delayed vaccination, and outright refusal of all vaccines. It has been defined by the Strategic Advisory Group of Experts (SAGE) on Immunization as "...delay in acceptance or refusal of vaccines despite availability of vaccination services. Vaccine hesitancy is complex and context specific, varying across time, place and vaccines. It is influenced by factors such as complacency, convenience and confidence." (15)

Vaccine hesitancy is recognized as a problem globally and has reached the attention of the World Health Organization to stimulate a more organized approach to this phenomenon $(16,17)$. Hesitancy is closely aligned with public trust in vaccines. It is not solely related to scientific issues but influenced by psychological factors, the sociocultural milieu, philosophical inclination such as preference for "natural" alternatives, and religious and political factors, including distrust of government and the pharmaceutical industry. While new immunization program introduction is traditionally concerned with the science of the vaccine and the infrastructure for its delivery, there has been insufficient attention to the many factors that influence public acceptance of vaccines (18).

Several reviews of the vaccine hesitancy literature have been published and a report outlining an evidence-based strategy was issued by SAGE following its October 2014 meeting $(15,19,20,21,22)$. While the literature contains a heterogeneous group of approaches, populations and results, SAGE supports delivery of multicomponent but integrated interventions that include mass media, social mobilization at multiple levels and dialogue-based interventions, in addition to previously identified effective strategies (e.g., reminder/recall). SAGE also concluded that more research is needed that is formative in nature and designed to obtain evidence rather than test pre-formed assumptions.

\section{Practitioner-based strategies}

Resources are available to help practitioners with the difficult dialogue with vaccine-hesitant parents. Emerging evidence supports starting the conversation with a statement assuming that the child will be immunized (an "optin" approach), which recognizes that parents perceive the decision as complex and emotional, and based on "choice architecture" observations that in such situations humans will choose a decision that has already been made by the majority (23). Available guidance advises listening to the parent's perspective and concerns in a nonjudgmental manner, and the importance of establishing trust. Motivational interviewing with open questions and a guiding style is recommended to identify whether the parent is responsive to change and their motivations, and to establish where they sit in the five-stage spectrum based on the transtheoretical model of behaviour change (precontemplation, contemplation, preparation, action, maintenance) (24).

Clinical practice guidelines from experts in the field advise that the dialogue should also elicit specific worries about information the parent has read or been told $(25,26,27)$. The literature suggests that standard written vaccine information and refuting misconceptions may further entrench parents most strongly opposed to vaccination (28). Evidence supports emphasizing the benefit to the child of being vaccinated instead of emphasizing benefits to society as a whole (29). Illustration through use of stories about cases of vaccinepreventable disease is more helpful than providing statistics, but it is important to define numerically terminology (e.g., "common" or "rare") that may be used to describe both the risk of disease and its complications and frequency of an adverse event.

The encounter is more effective when the information provided to the parent is tailored to their concerns. Providers should be well informed to address parents' questions, as research indicates that vague responses do 
not engender confidence; an excellent series of public domain articles is available in Pediatrics $(30,31,32,33)$. Providers should also be careful not to "oversell" immunization, to outline expectations and management of common adverse events, including local injection site reactions and fever in infants and young children, and to address parents' fear of their child's pain associated with injectable vaccines and to offer methods to reduce it (13). However, the provider should provide a clear recommendation, as this has been repeatedly recognized as highly associated with parental acceptance of vaccines. Much of this information has been summarized into online resources that can be readily accessed and also provided to parents $(34,35,36)$.

\section{Program strategies}

On a broader scale, other strategies are also worth exploring. These include use of trained lay people alongside a trained provider in group sessions with parents prior to commencing an immunization series (37), and timely public health response to negative media reports or shoddy science $(38,39)$. Engagement of the larger community supportive of vaccination in advocacy is also an emerging strategy that lends promise and will require evaluation $(40,41)$.

\section{Conclusion}

Despite the fact that vaccines are second only to clean water in saving lives across the globe, there is no magic bullet to address their acceptance (42). To ensure continued success of these programs, it is important to focus on population, community and individual concerns, to better understand where these lie on the continuum from acceptance to rejection. This knowledge and evidence-based multi-component approaches tailored to specific communities and vaccines are required to improve public acceptance of vaccines and achieve not only improved uptake but also increased trust and confidence.

\section{Acknowledgements}

I would like to acknowledge my many public health and pediatrics colleagues whose dedication and commitment to quality immunization programs is unwavering.

\section{Conflict of interest}

None

\section{Funding}

None

\section{References}

(1) Public Health Agency of Canada. Elimination of Measles, Rubella and Congenital Rubella Syndrome in Canada: Documentation and Verification Report. Executive Summary. 2013 Apr 4. http://www.phac-aspc.gc.ca/im/vpd-mev/measles-rougeole-mrer-eng.php.

(2) Ogilvie G, Anderson M, Marra F, McNeil S, Pielak K, Dawar M, Mclvor M, Ehlen T, Dobson S, Money D, Patrick DM, Naus M. A population-based evaluation of a publicly funded, school-based HPV vaccine program in British Columbia, Canada: Parental factors associated with HPV vaccine receipt. PLoS Med. 2010 May 4;7(5):e1000270.

(3) UNICEF Office of Research. Child well-being in rich countries: A comparative overview. Innocenti Report Card 11. Florence: UNICEF Office of Research; 2013. http://www.unicef-irc.org/publications/pdf/rc11_eng.pdf

(4) Canadian Immunization Conference 2014. Spēaker Presentations. Programs Panel Session 1. Tuesday December 2, 11:00 am, Room 210. Immunization Coverage in Canada. Presentations by Samara David (British Columbia) and Sarah Wilson (Ontario). http://cic2014.isiglobal.ca/calendar/1

(5) Public Health Agency of Canada (PHAC). The Chief Public Health Officer's Report on the State of Public Health in Canada 2013: Infectious Disease-The Never-ending Threat. Ottawa: PHAC; 2013. Page 9. http://www.phac-aspc.gc.ca/cphorsphc-respcacsp/2013/assets/pdf/2013-eng.pdf.

(6) Public Health Agency of Canada. Canadian Immunization Guide. 2014 Apr 23. 
http://www.phac-aspc.gc.ca/publicat/cig-gci/index-eng.php.

(7) Public Health Agency of Canada. Immunization Coverage in Canada (2002 to 2012). 2015 Jan 30. http://www.phac-aspc.gc.ca/im/nics-enva/icc-cvc-eng.php.

(8) Gyorkos TW, Tannenbaum TN, Abrahamowicz M, Bédard L, Carsley J, Franco ED, Delage G, Miller MA, Lamping DL, Grover SA. Evaluation of the effectiveness of immunization delivery methods. Can J Public Health. 1994 Jul-Aug;85 Suppl 1:S14-30.

(9) Tannenbaum TN, Gyorkos TW, Abrahamowicz M, Bédard L, Carsley J, Franco ED, Delage G, Miller MA, Lamping DL, Grover SA. Immunization delivery methods: Practice recommendations. Can J Public Health. 1994 Jul-Aug;85 Suppl 1:S37-4.

(10) Briss PA, Rodewald LE, Hinman AR, Shefer AM, Strikas RA, Bernier RR, Carande-Kulis VG, Yusuf HR, Ndiaye SM, Williams SM. Reviews of evidence regarding interventions to improve vaccination coverage in children, adolescents, and adults. The Task Force on Community Preventive Services. Am J Prev Med. 2000 Jan;18(1 Suppl):97-140.

(11) Task Force on Community Preventive Services. Recommendations Regarding Interventions to Improve Vaccination Coverage in Children, Adolescents, and Adults. Am J Prev Med. 2000;18(1S):92-6.

(12) Community Preventive Services Task Force. Topic: Vaccination-Increasing Appropriate Vaccination. Community Guide Branch. Division of Public Health Information Dissemination. Center for Surveillance, Epidemiology and Laboratory Services. Office of Public Health Scientific Services. Centers for Disease Control and Prevention. 2015 Feb 13. http://www.thecommunityguide.org/vaccines/index.html

(13) Taddio A, Appleton M, Bortolussi R, Chambers C, Dubey V, Halperin S, Hanrahan A, Ipp M, Lockett D, MacDonald N, Midmer D, Mousmanis P, Palda V, Pielak K, Riddell RP, Rieder M, Scott J, Shah V. Reducing the pain of childhood vaccination: An evidence-based clinical practice guideline. CMAJ. 2010 Dec14;182(18):E843-55.

(14) Jacobson RM, Targonski PV, Poland GA. A taxonomy of reasoning flaws in the anti-vaccine movement. Vaccine. 2007 Apr 20;25(16):3146-52.

(15) Report of the SAGE Working Group on Vaccine Hesitancy. 2014 Nov 12. http://www.who.int/immunization/sage/meetings/2014/october/SAGE_working_group_revised_report_vaccine_hesita ncy.pdf?ua=1

(16) Streefland P, Chowdhury AM, Ramos-Jimenez P. Patterns of vaccination acceptance. Soc Sci Med. 1999 Dec;49(12):1705-16.

(17) Dubé E, Gagnon D, Nickels E, Jeram S, Schuster M. Mapping vaccine hesitancy-Country-specific characteristics of a global phenomenon. Vaccine. 2014 Nov 20;32(49):6649-54.

(18) Larson HJ, Cooper LZ, Eskola J, Katz SL, Ratzan S. Addressing the vaccine confidence gap. Lancet. 2011 Aug 6;378(9790):526-35.

(19) Dubé E, Laberge C, Guay M, Bramadat P, Roy R, Bettinger J. Vaccine hesitancy: An overview. Hum Vaccin Immunother. 2013 Aug;9(8):1763-73.

(20) Larson HJ, Jarrett C, Eckersberger E, Smith DM, Paterson P. Understanding vaccine hesitancy around vaccines and vaccination from a global perspective: A systematic review of published literature, 2007-2012. Vaccine. 2014 Apr 17;32(19):2150-9.

(21) Gowda C, Dempsey AF. The rise (and fall?) of parental vaccine hesitancy. Hum Vaccin Immunother. 2013 Aug;9(8):1755-62.

(22) Sadaf A, Richards JL, Glanz J, Salmon DA, Omer SB. A systematic review of interventions for reducing parental vaccine refusal and vaccine hesitancy. Vaccine. 2013 Sep 13;31(40):4293-304.

(23) Opel DJ, Omer SB. Measles, mandates, and making vaccination the default option. JAMA Pediatr. 2015 Feb 11. doi: 10.1001/jamapediatrics.2015.0291. [Epub ahead of print] PubMed PMID: 25671505.

(24) Leask J, Kinnersley P, Jackson C, Cheater F, Bedford H, Rowles G. Communicating with parents about vaccination: A framework for health professionals. BMC Pediatr. 2012 Sep 21;12:154.

(25) Halperin S. How to manage parents unsure about immunization. Canadian Journal of CME. 2000 Jan:62-75. www.path.org/vaccineresources/details.php?i=152

(26) MacDonald NE, Finlay JC, Canadian Paediatric Society Infectious Diseases and Immunization Committee. Working with vaccine-hesitant parents. Paediatr Child Health. 2013;18(5):265-7.

http://www.cps.ca/documents/position/working-with-vaccine-hesitant-parents

(27) Healy CM, Pickering LK. How to communicate with vaccine-hesitant parents. Pediatrics. $2011 \mathrm{May} ; 127$ Suppl $1:$ S127-33.

(28) Nyhan B, Reifler J, Richey S, Freed GL. Effective messages in vaccine promotion: A randomized trial. Pediatrics. 2014 Apr;133(4):e835-42. 
(29) Hendrix KS, Finnell SM, Zimet GD, Sturm LA, Lane KA, Downs SM. Vaccine message framing and parents' intent to immunize their infants for MMR. Pediatrics. 2014 Sep;134(3):e675-83.

(30) Offit PA, Moser CA. The problem with Dr Bob's alternative vaccine schedule. Pediatrics. 2009 Jan;123(1):e164-9.

(31) Offit PA, Jew RK. Addressing parents' concerns: Do vaccines contain harmful preservatives, adjuvants, additives, or residuals? Pediatrics. 2003 Dec;112(6 Pt 1):1394-7.

(32) Offit PA, Hackett CJ. Addressing parents' concerns: Do vaccines cause allergic or autoimmune diseases? Pediatrics. 2003 Mar;111(3):653-9.

(33) Offit PA, Quarles J, Gerber MA, Hackett CJ, Marcuse EK, Kollman TR, Gellin BG, Landry S. Addressing parents' concerns: Do multiple vaccines overwhelm or weaken the infant's immune system? Pediatrics. 2002 Jan;109(1):124-9.

(34) Derban A, Harper J, Jiwa S, et al. ImmunizeBC. Quick Reference: Immunization Communication Tool for Immunizers. 2013.

http://www.immunizebc.ca/sites/default/files/docs/ict final.pdf

(35) Centers for Disease Control and Prevention, American Academy of Family Physicians, American Academy of Pediatrics. Provider Resources for Vaccine Conversations with Parents. 2014 Dec 17. http://www.cdc.gov/vaccines/hcp/patient-ed/conversations/index.html

(36) Canadian Paediatric Society. Your Child's Best Shot: A parent's guide to vaccination. 4th ed. Moore DL, editor. 2015. https://bookstore.cps.ca/stock/details/your-childs-best-shot-a-parents-guide-to-vaccination-4th-edition

(37) Jackson C, Cheater FM, Harrison W, Peacock R, Bekker H, West R, Leese B. Randomised cluster trial to support informed parental decision-making for the MMR vaccine. BMC Public Health. 2011 Jun 16;11:475.

(38) Nicholson MS, Leask J. Lessons from an online debate about measles-mumps-rubella (MMR) immunization. Vaccine. 2012 May 28;30(25):3806-12.

(39) Centers for Disease Control and Prevention. Clinical Immunization Safety Assessment (CISA) Network Publications and Technical Reports. Technical Reports. Review of a published report of cerebral vasculitis after vaccination with the Human Papillomavirus (HPV) Vaccine. 2012 Nov 9.

http://www.cdc.gov/vaccinesafety/Activities/cisa/technical_report.html

(40) Within Reach. What can parents do to support immunization? Seattle, WA; 2015 Feb 13.

http://www.withinreachwa.org/what-can-parents-do-to-support-immunization/

(41) I Boost Immunity, BC. Sponsored by the Public Health Association of BC. http://www.iboostimmunity.ca/

(42) Andre FE, Booy R, Bock HL, Clemens J, Datta SK, John TJ, Lee BW, Lolekha S, Peltola H, Ruff TA, Santosham M, Schmitt HJ. Vaccination greatly reduces disease, disability, death and inequity worldwide. Bull World Health Organ. 2008 Feb;86(2):140-6. 